www.jmscr.igmpublication.org

Index Copernicus Value: 79.54

ISSN (e)-2347-176x ISSN (p) 2455-0450

crossrefDOI: https://dx.doi.org/10.18535/jmscr/v7i2.84

\title{
Redefining risk factors associated with Acute Myocardial Infarction (AMI) and to define independent predictors of mortality and morbidity in AMI
}

\author{
Authors \\ Viral Sangwan, Dr Roopa Malik, Dr Manjari Garg, Dr Sanjay Fotedar \\ PGIMS Rohtak \\ Email: drviralsangwan@yahoo.com, Mobile: 9896130304
}

\begin{abstract}
Objective: To study various risk factors associated with Acute Myocardial Infarction, to define independent predictors of mortality and morbidity in AMI and to compare our mortality rate with those published from centre having PCI/CABG facilities.

Method: This was a prospective study on 200 consecutive patients of acute myocardial infarction admitted to intensive cardiac care unit of PGIMS Rohtak for one year duration. Clinical and demographic profile, risk factors, morbidity and mortality of AMI patients were studied, analyzed and compared to results from centers having PCI/CABG facilities.

Results: Factors associated with increased morbidity are age $>70$ years, female gender, $>10$ hours duration of chest pain, tachycardia (>100bpm), hypotension (systolic BP 100 $\mathrm{mmHg}$ ), hypertension, socioeconomic status (class III, IV, V), diabetes, obesity, sedentary life style, LDL cholesterol $<140 \mathrm{mg} \%$, $S$. homocystine $>12 \mathrm{umol} / \mathrm{L}, \mathrm{S}$. cholesterol $>240 \mathrm{mg} / \mathrm{dl}$, presence of multiple risk factors. Independent predictors of mortality include age $>70$ years, female gender, duration of chest pain $>10$ hours, tachycardia, hypotension, not receiving treatment outside hospital, previous history of MI, history of diabetes, physical inactivity, S. total cholesterol $>240 \mathrm{mg} \%$, LDL cholesterol $>130 \mathrm{mg} \%$, HDL cholesterol $<40 \mathrm{mg} \%$, S. homocystine $>12 \mathrm{umol} / \mathrm{L}$ and presence of multiple risk factors. On follow up, most common complication was LVF and post MI angina. Total mortality rate in this one year study was 3\%.Total mortality rate of last 5 years data was $4.49 \%$. Centers having PCI facilities had $6.4 \%$ mortality in AMI patients.
\end{abstract}

Keywords: Acute myocardial infarction, risk factors, mortality, morbidity.

\section{Introduction}

Coronary heart disease (CHD), also known as coronary artery disease is a leading cause of morbidity and mortality in western countries. Angina pectoris and acute myocardial infarction are the two most common presentations of CHD. Other features of CHD include coronary insufficiency (prolonged ischemic- type chest pain accompanied by transient ST segment or T wave changes in electrocardiogram) and sudden unexpected death (death within an hour of onset of symptoms when no other disease be accountable). In today's world a major share of deaths are attributable to non-communicable diseases and just over half of these are as a result of cardiovascular diseases. More than one third of these occur in middle aged adults. In developed countries heart diseases and stroke are the first 
and second leading causes of death for adult men and women. Surprisingly in some of the developing countries also cardiovascular disease has become the leading cause of mortality. ${ }^{1}$

To reduce the incidence of $\mathrm{CHD}$, what is required is sufficient knowledge in understanding the causes and risk factors associated with the disease. The disease has a multifactorial etiology and in India the commonest risk factors are smoking, diabetes mellitus and hypertension.

Hyperlipidemia which is a leading cause in western countries has been observed in lesser percentage of cases in India. In our population the disease strikes at an early age and much more commonly affects males than females. Other risk factors encountered are truncal obesity, hyperlipidemia, genetic predisposition, sedentary life style and hyperhomocysteinemia.

The mortality rate in the pre CCU era has been reported to be around $30 \%$. The mortality dropped dramatically to about 15 percent in $\mathrm{CCU}$ era, which embraced the use of hemodynamic monitoring, defibrillation and use of beta blockers. Increased use of thrombolytics, coronary interventions, aspirin and ACE inhibitors has further decreased the mortality rate in patients of conventional ST segment elevated AMI to 6-7\%. ${ }^{2}$ Hedayati et al conducted a study in 175 consecutive unselected patients suspected of having AMI who were admitted in coronary care unit.100 of these proven to have AMI. These patients were compared with another 100 cases of AMI who were admitted to hospital in the period immediately preceding establishment of CCU. They found that mortality in patient admitted in CCU was $11 \%$ compared to $31 \%$ not admitted in CCU. ${ }^{3}$ In our hospital ICCU facilities are available but we do not have PCI facilities. It is desirable to study mortality rate, complications and risk factors in our patients admitted to ICCU and compare the results available in literature from most modern ICCU's having PCI facilities. The present study is an attempt to study in hospital mortality and morbidity trends in acute myocardial infarction and to identify independent predictors of mortality and to compare our mortality rate with those published from centre having PCI/CABG facilities.

\section{Material and Methods}

200 consecutive patients of AMI who were admitted to ICCU formed the study group. The diagnosis of AMI was based on the following criteria:

1. Typical chest pain lasting $>30$ minutes.

2. Typical ECG changes (ST elevation $>1 \mathrm{~mm}$ in $\geq 2$ consecutive leads).

3. Cardiac enzyme levels exceeding at least two times the upper limits.

Immediately on arrival in the hospital a detailed history and physical examination was recorded in a specially designed performa. Special note was taken of age, sex, time elapsed from onset of chest pain to arrival in hospital, past history of angina and treatment, family history of ischemic heart disease, established risk factors, smoking, diabetes mellitus, hypertension, hyperlipidemia, obesity, socio-economic status, physical activity, serum uric acid, serum homocystine.

Blood samples were taken for estimation of cardiac enzymes (CPK-MB, SGOT/PT), blood sugar, blood urea, serum creatinine, serum uric acid, serum sodium, serum potassium, lipid profile. Homocystine estimation was done in patients who could afford that. ECG record was carefully scrutinized to categorize the site of infarction. A baseline skiagram was done. A pre discharge echocardiography was done in all patients. Those patients who reported within 12 hours from onset of chest pain were thrombolysed. Standard treatment was given to all patients and details of each drug administered were recorded. A special note was made of each minor/major complication developing during the hospital stay especially cardiac arrhythmias including blocks, cardiogenic shock, recurrent angina/re infarction, heart failure, pericarditis, CVA, DVT and pulmonary embolism.

All efforts were made to assign immediate cause of death in non survivors and factors contributing 
to mortality identified. Those patients who required urgent intervention (PCI, stenting /CABG) were referred and allowed to go to centers where these facilities are available. All patients were followed up at one month and TMT was performed to do risk stratification (unless contraindicated) in all cases.

Data was analyzed to find mortality rate, major morbid events, factors contributory to mortality and compared with data reported from centers having PCI/CABG facilities.

\section{Observations}

Age wise distribution and related morbidity and mortality of AMI patients has been shown in table 1.Maximum no. of patients were in 40-70 age group. While higher mortality was seen in 70 year above age group.

Table 1 Showing age distribution and effect of age on morbidity and mortality in AMI patients.

\begin{tabular}{|l|c|c|c|}
\hline Age group & No of patients & Morbidity & Mortality \\
\hline $20-29$ & 1 & 0 & 0 \\
\hline $30-39$ & 21 & 1 & 0 \\
\hline $40-49$ & 50 & 7 & 0 \\
\hline $50-59$ & 52 & 8 & 1 \\
\hline $60-69$ & 51 & 6 & 0 \\
\hline $70-79$ & 23 & 7 & 4 \\
\hline $80 \&$ above & 2 & 0 & 2 \\
\hline Total & 200 & 29 & 7 \\
\hline
\end{tabular}

Risk factor profile in AMI patients and their relation to morbidity and mortality has been shown in table 2 and table 3 respectively. Male predominance $(87.5 \%)$ was seen in AMI patients as compared to females (12.5\%). Morbidity and mortality was higher in females as compared to males $(25 \%$ vs $13.7 \%$ and $4 \%$ vs $2.9 \%$ respectively).

Table 2 Association of various risk factors in AMI patients

\begin{tabular}{|l|c|c|}
\hline Risk factor & Present & Absent \\
\hline Male factor & $175(87.5 \%)$ & $25(12.5 \%)$ \\
\hline Smoking & $167(84 \%)$ & $33(16 \%)$ \\
\hline Hypertension & $38(19 \%)$ & $162(81 \%)$ \\
\hline Diabetes mellitus & $11(5.5 \%)$ & $189(94.5 \%)$ \\
\hline Anemia $(\mathrm{Hb} \leq 10 \mathrm{gm} \%)$ & $81(41.33 \%)$ & $115(58.88 \%)$ \\
\hline History of previous MI & $22(11 \%)$ & $178(89 \%)$ \\
\hline Obesity (BMI $\left.>30 \mathrm{~kg} / \mathrm{m}^{2}\right)$ & $61(30.5 \%)$ & $139(69.5 \%)$ \\
\hline Physical activity & $142(71 \%)$ & $58(29 \%)$ \\
\hline Family history of IHD & $17(8.5 \%)$ & $183(91.5 \%)$ \\
\hline $\begin{array}{l}\text { Hyperhomocystinemia } \\
(\geq 12 \mu \text { mol/l) }\end{array}$ & $124(76.74 \%)$ & $38(23.46 \%)$ \\
\hline
\end{tabular}

\begin{tabular}{|l|c|c|}
\hline $\begin{array}{l}\text { Serum total cholesterol } \\
>200 \mathrm{mg} \%\end{array}$ & $46(23.48 \%)$ & $150(76.52 \%)$ \\
\hline LDL cholesterol $(\geq 130 \mathrm{mg} \%)$ & $39(19.9 \%)$ & $157(80.1 \%)$ \\
\hline HDL cholesterol $(<40 \mathrm{mg} \%)$ & $106(54 \%)$ & $90(46 \%)$ \\
\hline
\end{tabular}

Factors associated with increased morbidity were age $>70$ years, female gender, $>10$ hours duration of chest pain before reaching hospital, tachycardia (>100bpm), hypotension (systolic BP $<100 \mathrm{~mm}$ $\mathrm{Hg}$ ), hypertension, socioeconomic status (class III, IV,V), diabetes, obesity, sedentary life style, LDL cholesterol $>130 \mathrm{mg} \%$, HDL cholesterol $\leq$ $140 \mathrm{mg} \%$, S. homocystine, s.cholesterol $>240 \mathrm{mg} \%$, presence of multiple risk factors.

Independent predictors of mortality were age $>70$ years, female gender, duration of chest pain $>10$ hours, tachycardia, hypotension, not receing treatment outside hospital, previous history of AMI, history of diabetes, physical inactivity, s. cholesterol >240 $\mathrm{mg} \%, \quad \mathrm{LDL}$ cholesterol $>130 \mathrm{mg} \%$, HDL cholesterol<40mg\%, s. homocystine $>12 \mathrm{umol} / \mathrm{L}$ and presence of multiple risk factors.

Table 3 Effect of various risk factors on morbidity and mortality in AMI patients

\begin{tabular}{|c|c|c|c|}
\hline Risk factor & & Morbidity & Mortality \\
\hline Sex & $\begin{array}{l}\text { Male } 175 \\
\text { Female } 25\end{array}$ & $\begin{array}{c}24(14 \%) \\
5(20 \%)\end{array}$ & $\begin{array}{c}5(2.8 \%) \\
1(4 \%)\end{array}$ \\
\hline Smoking & $\begin{array}{l}\text { Yes (167) } \\
\text { No (33) }\end{array}$ & $\begin{array}{l}21(13 \%) \\
8(24.2 \%)\end{array}$ & $\begin{array}{l}2(1.2 \%) \\
4(12.1 \%)\end{array}$ \\
\hline Hypertension & $\begin{array}{l}+(38) \\
-(162)\end{array}$ & $\begin{array}{l}11(29 \%) \\
18(12 \%)\end{array}$ & $\begin{array}{l}1(3 \%) \\
5(3 \%)\end{array}$ \\
\hline Diabetes & $\begin{array}{l}+(11) \\
-(189)\end{array}$ & $\begin{array}{c}4(36.4 \%) \\
25(13.2 \%)\end{array}$ & $\begin{array}{c}1(9.1 \%) \\
5(2.64 \%)\end{array}$ \\
\hline S. cholesterol (mg\%) & $\begin{array}{l}<200(150) \\
>200(46)\end{array}$ & $\begin{array}{l}10(6.67 \%) \\
19(41.3 \%)\end{array}$ & $\begin{array}{c}0 \\
2(11.8 \%)\end{array}$ \\
\hline LDL cholesterol (mg\%) & $\begin{array}{l}\leq 130(157) \\
>130(39)\end{array}$ & $\begin{array}{c}7(4.46 \%) \\
22(56.4 \%)\end{array}$ & $\begin{array}{l}1(0.64 \%) \\
1(2.57 \%)\end{array}$ \\
\hline HDL cholesterol (mg\%) & $\begin{array}{l}\leq 40(106) \\
>40(90)\end{array}$ & $\begin{array}{c}18(17 \%) \\
11(12.2 \%)\end{array}$ & $\begin{array}{c}2(1.9 \%) \\
0\end{array}$ \\
\hline $\begin{array}{l}\text { Hyperhomocysteinemia } \\
(\mu \mathrm{mol} / \mathrm{l})\end{array}$ & $\begin{array}{l}<12(38) \\
>12(124)\end{array}$ & $\begin{array}{c}1(2.64 \%) \\
23(18.55 \%)\end{array}$ & $\begin{array}{c}0 \\
1(0.81 \%)\end{array}$ \\
\hline $\mathrm{Hb}(\mathrm{gm} \%)$ & $\begin{array}{l}<10(81) \\
>10(115)\end{array}$ & $\begin{array}{c}10(12.3 \%) \\
19(16.53 \%)\end{array}$ & $\begin{array}{l}11.24 \%) \\
1(0.87 \%)\end{array}$ \\
\hline H/O Previous MI & $\begin{array}{l}+(22) \\
-(178) \\
\end{array}$ & $\begin{array}{c}3(13.6 \%) \\
26(14.61 \%)\end{array}$ & $\begin{array}{l}3(13.64 \%) \\
3(1.679 \%) \\
\end{array}$ \\
\hline Obesity & $\begin{array}{l}+(61) \\
-(139)\end{array}$ & $\begin{array}{c}20(32.79 \%) \\
9(6.48 \%)\end{array}$ & $\begin{array}{c}6(9.84 \%) \\
0\end{array}$ \\
\hline Family history & $\begin{array}{l}+(17) \\
-(183)\end{array}$ & $\begin{array}{l}2(11.77 \%) \\
27(14.8 \%)\end{array}$ & $\begin{array}{c}0 \\
6(3.3 \%)\end{array}$ \\
\hline Physical activity & $\begin{array}{c}+(142) \\
-(58)\end{array}$ & $\begin{array}{l}11(7.75 \%) \\
18(31.04 \%)\end{array}$ & $\begin{array}{c}2(1.41 \%) \\
4(6.9 \%)\end{array}$ \\
\hline Tachycardia(100/min) & $\begin{array}{l}+(30) \\
-(170)\end{array}$ & $\begin{array}{c}10(33.32 \%) \\
19(11.2 \%)\end{array}$ & $\begin{array}{c}5(16.67 \%) \\
1(0.5 \%)\end{array}$ \\
\hline Bradycardia $(<60 / \mathrm{min})$ & $\begin{array}{l}+(9) \\
-(191) \\
\end{array}$ & $\begin{array}{c}2(22.23 \%) \\
27(14.14 \%) \\
\end{array}$ & $\begin{array}{c}0 \\
6(3.15 \%) \\
\end{array}$ \\
\hline $\begin{array}{ll}\text { Hypotension } \quad \text { (systolic }\end{array}$ & $+(50)$ & $8(16.67 \%)$ & $3(6 \%)$ \\
\hline
\end{tabular}




\begin{tabular}{|l|c|c|c|}
\hline BP<100mmHg) & $-(150)$ & $21(14 \%)$ & $3(2 \%)$ \\
\hline T/t outside hospital & $+(34)$ & $6(18 \%)$ & 0 \\
& $-(166)$ & $23(14 \%)$ & $6(4 \%)$ \\
\hline SE status & iii, iv, & $21(14.3 \%)$ & $3(2.06 \%)$ \\
& $\mathrm{v}(146)$ & $8(6.75 \%)$ & $3(5.6 \%)$ \\
& $\mathrm{i}, \mathrm{ii}(54)$ & & \\
\hline Duration of chest pain & $<10$ hours & 25 & 5 \\
& $(186)>10$ & $4(28.5 \%)$ & $1(7.1 \%)$ \\
& hours(14) & & \\
& \multicolumn{3}{|c}{} \\
\end{tabular}

In our study 111 patients had anterior wall MI, of these 19 patients had complications and 4 patients died. There was no significant relation between location of infarct and morbidity and mortality.

Table 4 Effect of location of MI on morbidity and mortality

\begin{tabular}{|l|c|c|c|}
\hline & No of patients & Morbidity & Mortality \\
\hline AWMI & 111 & $19(17 \%)$ & $4(3.1 \%)$ \\
\hline IWMI & 84 & $8(9.5 \%)$ & $2(2.38 \%)$ \\
\hline LWMI & 3 & $1(33.3 \%)$ & 0 \\
\hline A+IWMI & 2 & $1(50 \%)$ & 0 \\
\hline
\end{tabular}

\section{Discussion}

Vast majority of Indian population resides in rural areas where medical facilities are grossly inadequate. Even in district towns and cities facilities for $\mathrm{PCI} / \mathrm{CABG}$ are at very limited centers and wherever available it is at an exharibant cost. Thus these facilities are available to not more than $5 \%$ of total population and remaining $95 \%$ population can not avail the benefits of these advancement in the treatment of CAD. There are reports that in patients of acute myocardial infarction 30 day mortality/morbidity is not significantly different in centers having PCI facilities as those without these. ${ }^{4,5}$

The risk factor profile has also been reported different from different places. Our institution caters to a large area of rural and urban district town. The study was aimed at comparing the mortality/morbidity rates at our setting (which is devoid of PCI facility) vis a vis other centers having these facilities and also to study the clinical profile of disease as prevalent in our population.

Out of total 200 consecutive patients admitted as many as 175 were males giving a male: female ratio of 7:1 which indicates very high preponderance of disease in males. The disease has started affecting more and more young people $^{14}$. Our youngest patient was age of 29 years and $11 \%$ patients were below 40 years of age. However, the mortality rate in relation to age increased with advancement in age as it was maximum in the age group 70-79 years. None of our patients below 50 years of age died. Singh et al in their study found similar results as our study as $4 \%$ death in young age group (45 years) as compared to $16 \%$ in old age group. The overall 7 days mortality in our series was 3\%. This is less than the mortality rates reported from other centers where invasive procedures (PCI) are being done routinely. The data strongly suggests that thrombolytic therapy coupled with invasive monitoring and judicious use of other pharmacological agents like $\beta$-blockers, ramipril, antiplatelets and nitrites effectively reduces mortality/morbidity in acute myocardial infarction. Still more important is the role of invasive monitoring in ICCU as earliest appropriate treatment for arrhythmias and left ventricular dysfunction which are the commonest cause of morbidity and mortality in acute myocardial infarction. The incidence of post infarction angina in our series was $11.5 \%$ which is higher than the reported from centers having PCI facilities. ${ }^{6}$ This is obviously due to the fact that thrombolysis tackles the fresh clot and establishes vessel patency but the atherosclerotic plaques (narrowings) remain unaffected and are the cause of subsequent angina. Our TMT results confirms this as out of 200 patients 191 undergone TMT, 97 patients $(50.8 \%)$ had positive TMT and 94 (49.2\%) had negative TMT.47 TMT negative patients had some complications in follow up period of 1 month.

Duration of chest pain till revascularization (thrombolysis /PCI) has been considered as an important predictor of mortality. We found that none of our patients who reached within 2 hours of chest pain died. Our findings confirm the dictum that time is muscle as initial few hours are the most crucial in salvaging myocardium from ischemic insult. ${ }^{7,17}$ 
In our study we observed that smoking is the most prevalent major coronary risk factor present in $84 \%$ patients, results of other studies are also consistent with our study. ${ }^{8}$ It was interesting to observe that mortality rate was higher in non smokers compared to smokers.2 out of 167 smokers died, whereas 4 out of 33 non smokers died giving a mortality rate of $12.1 \%$. Even the morbidity was higher in non smokers $(24.2 \%)$ compared to smokers (13\%). The findings are contrary to the accepted fact that smoking is a major risk factor for CAD. However partly the results might have been vitiated by the small number of patients (33 only) in non smoker group compared to 167 patients in smoker group. Our results are consistent with Barbash et al who found that smokers had significantly better hospital outcome than non smokers or ex smokers. ${ }^{9}$ Stig et al also concluded that smoking was associated with reduced 30 days and long term mortality as smokers were on an average 10 years younger, had fewer concomitant cardiac risk factors and were more likely to be male and to receive thrombolytic therapy more frequently than non smokers. ${ }^{10}$

The $2^{\text {nd }}$ most prevalent coronary risk factor in our patients was hypertension which was present in $19 \%$ of our cases. As many as 11 (29\%) out of total 38 hypertensive patients developed some complication (mostly LVF) and one of them died (mortality rate $2.64 \%$ ). Diabetes was the next very important risk factor detected in $5.5 \%$ cases and $36.4 \%$ of them had one or the other complication and one of the diabetic patient died giving a mortality rate of $9.1 \%$. Our results are similar to studies done by Limbderog $\mathrm{V}$ and Daniel and Singh et al who found mortality to be greater in diabetic patients as compared to non diabetic patients. ${ }^{11,12}$ In this study 30 patients (15\%) had tachycardia. Of these $10(35.7 \%)$ patients had complications and $3(11 \%)$ patients had mortality, therefore tachycardia was an independent predictor of mortality. Hypotension was present in 50 patients, of whom 8 had complications and 4 expired. In our study 34 patients received outside hospital and 8 had complication and no mortality was seen.

$61(30.5 \%)$ patients were obese in our study. Of whom $20(32.79 \%)$ had complications while 6 (9.84\%) expired. Therefore obesity was a significant factor associated with morbidity and mortality in AMI patients. Only $8.5 \%$ of patients had positive family history of IHD, of these 2 had some complications while no patient expired. In our study we found that $71 \%$ patients were physically active, of these 11 had complications while 58 were not physically active, of these $31 \%$ had complications and 4 patients expired. In our study $22(11 \%)$ patients had previous MI, of these 3 had morbidity and 3 had mortality, it was found to be an independent predictor of mortality. 146 patients $(73 \%)$ belonged to class III,IV,V socioeconomic status, of these 21 patients had complications and 3 patients expired.

Out of 196 patients whom serum cholesterol was measured $76.52 \%$ had serum cholesterol $<200 \mathrm{mg} \%$, of these $6.67 \%$ had complications and no patient expired. In patients who had $\mathrm{S}$. cholesterol $>240 \mathrm{mg} \% .88 .24 \%$ had complications and $11.8 \%$ had mortality, so serum cholesterol $>240 \mathrm{mg} \%$ can be taken as an independent predictor of mortality. Of 196 patients 39 patients had LDL cholesterol $>130 \mathrm{mg} \%$, of these 22 had complications and there was one mortality, so LDL cholesterol $>130 \mathrm{mg} \%$ can be taken as independent predictor of mortality. Of 196 patients 106 patients had LDL cholesterol $<40 \mathrm{mg} \%$, of these 18 patients had morbidity and 2 patients expired. So HDL cholesterol <40mg\% can be taken as an independent predictor of mortality.

Serum homocystine was measured in 162 patients of these 124 patients had high $(>12 \mathrm{umol} / \mathrm{ml})$ and 38 patients had normal. Mortality $(0.81 \%)$ and morbidity $(18.55 \%)$ were higher in patients who had serum homocystine $>12 \mathrm{umol} / \mathrm{ml}$. 194 patients were followed till 1 month after discharge. Of these 23 had CHF, 23 had post MI angina, 2 had reinfarction and 2 had cardiac arrest. 
Pair $\mathrm{P}$ et al studied differences in pattern of practice and outcome of acute coronary syndromes between tertiary (with cath lab) and secondary care centers in 4081 patients in 71 centers and concluded that at 30 days follow up there was no difference in mortality between tertiary and secondary centers $(7.9 \%$ vs $6.7 \%) .^{5}$ Zahn $\mathrm{R}$ et al studied mortality of AMI patients who had undergone primary angioplasty and found it to be $6.4 \%$.In our study mortality of last 5 year is $4.49 \%$ and mortality of 1 year study in 200 patients is $3 \% .^{13}$

\section{Conclusion}

The study concluded that acute myocardial infarction is more common in males. Chest pain is most common mode of presentation. AWMI is the most common site of location of infarction. Smoking is the commonest risk factor. The study also concluded that factors associated with increased morbidity are age $>70$ years, female gender, >10 hours duration of chest pain, tachycardia ( $>100 \mathrm{bpm}$ ), hypotension (systolic BP $100 \mathrm{mmHg}$ ), hypertension, socioeconomic status (class III, IV, V), diabetes, obesity, sedentary life style, LDL cholesterol $<140 \mathrm{mg} \%$, S. homocystine $>12 \mathrm{umol} / \mathrm{L}, \mathrm{S}$. cholesterol $>240 \mathrm{mg} / \mathrm{dl}$, presence of multiple risk factors.

Independent predictors of mortality include age $>70$ years, female gender, duration of chest pain $>10$ hours, tachycardia, hypotension, not receiving treatment outside hospital, previous history of MI, history of diabetes, physical inactivity, S. total cholesterol $>240 \mathrm{mg} \%$, LDL cholesterol $>130 \mathrm{mg} \%$, HDL cholesterol $<40 \mathrm{mg} \%$, S. homocystine $>12 \mathrm{umol} / \mathrm{L}$ and presence of multiple risk factors ${ }^{15,16}$.

On follow up most common complication was LVF and post MI angina. Total mortality rate in this one year study was $3 \%$. Total mortality rate of last 5 years data was $4.49 \%$.Centers having PCI facilities had $6.4 \%$ mortality in AMI patients.

\section{References}

1. WHO 2003. Shaping the Future. The World Health Report 2003.

2. Valentin F, Wayur RA, Robert AD, Roule O. ST segment elevation, Myocardial infarction: Clinical presentation, diagnostic evaluation and medical management. In: Hurst's The Heart. $11^{\text {th }}$ ed.p.1333.

3. Hedayati HA, Farivar S. The role of coronary care unit in reduction in mortality rate and sudden death in acute myocardial infarction. Pahlavi Med J 1977; 8(2):198207.

4. Maynard C, Weaver D, Litwin PE, Martin JS, Kudenchuk PJ, Dewhurst TA et al. Hospital mortality in acute myocardial infarction in the era of reperfusion therapy (the myocardial infarction triage and intervention project). Am J Cardiol 1993; 72: 877-82.

5. Pair P, Xavier D, Gupta R. Treatment and outcome of acute coronary syndromes: Does the hospital make a difference. Indian Heart J 2002; 54: 477-82.

6. Parisi AF, Folland ED, Hartigan P. A comparison of angioplasty with medical therapy in treatment of single- vessel coronary artery disease. N Eng J Med 1992; 326(1): 10-6.

7. Schomig A, Ndrepepa G, Mehilli J. Therapy dependent influence of time of treatment interval on myocardial salvage in patients with acute myocardial infarction treated with coronary artery stenting or thrombolysis. Circulation 2003; 108: 10848.

8. Park CK. Epidemiology of chronic noncommunicable diseases and conditions. In: Park's text book of preventive and social medicine. $17^{\text {th }}$ ed. Jabalpur; Banarsidas Bhanot; 2002; 272-307.

9. Barbash GI, Harvey DW, Michaela M. Significance of smoking in patients receiving thrombolytic therapy for acute 
myocardial infarction. Circulation 1993;87:

53-7.

10. Stig J, Kober L, Ottensen MM. The prognostic importance of smoking status at the time of acute myocardial infarction in 6676 patients. J Cardiovasc Risk 1999; 6: 23-7.

11. Lundberg V, Stegmayr B, Asplund K. Diabetes as a risk factor for myocardial infarction: population and gender perspectives. J Int Med 1997; 241: 485-92.

12. Daniel ES, Moulton AV, David MN. Interaction of diabetes with other preinfarction risk factors. Diabetes 1989; 38: 350-57.

13. Zahn R, Schiele R, Schneider S. Primary angioplasty versus intravenous thrombolysis in acute myocardial infarction: can define subgroups of patients of patients benefiting most from primary angioplasty? Results from pooled data of the Maximal Individual Therapy in Acute Myocardial Infarction Registry and MI Registry. J Am Coll Cardio 2001; 37(7): 1827-35.

14. Goliasch G, Orarce S, Blessberger H. Relative importance of different lipid risk factors for the development of myocardial infarction at a very young age ( $\leq 40$ years of age). Eur J Clin Invest 2012; 42(6): 631-6.

15. Canto JG, kiefe CI, Rogers WJ. Number of coronary heart disease risk factors and mortality in patients with first myocardial infarction. Jama 2011;30(19):2120-27.

16. Gili M, Sala J, Lopez J. Impact of comorbidities on in-hospital mortality from acute myocardial infarction 2003-2009. Rev Esp Cardiol 2011;64(12):1130-37.

17. Mun KJ, knudson AD, Klug MG. In hospital mortality among rural medicare patients with acute myocardial infarction: the influence of demographics, transfer and health risk factors. J Rural Health 2011;27(4):394-400. 